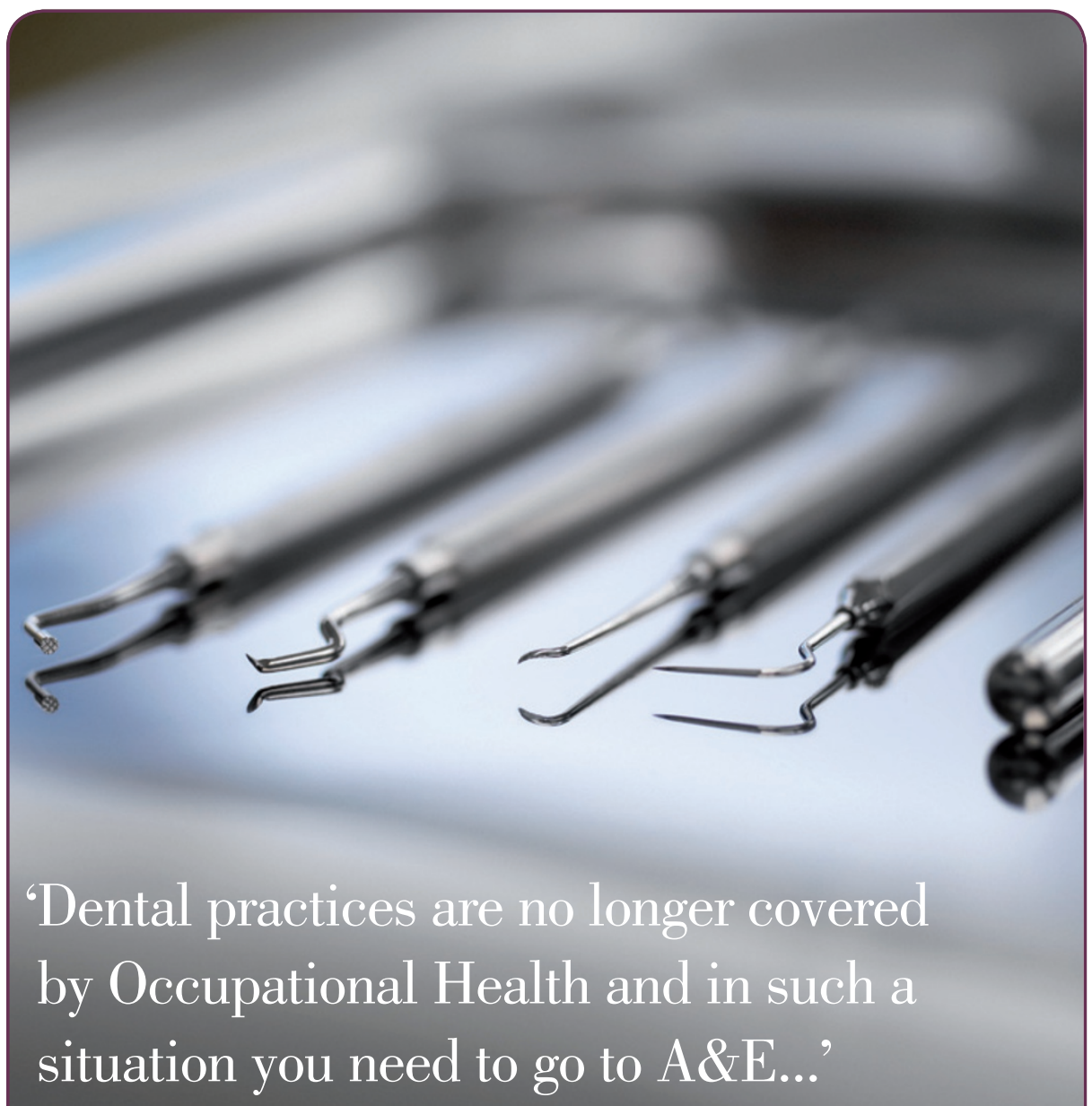

\section{RESPONDING TO SHARPS INJURIES}

Last week one of our staff had a sharps injury and hurt herself with a used probe. We contacted Occupational Health according to the rules of the practice. It turned out that dental practices are no longer covered by Occupational Health and in such a situation you need to go to $\mathrm{A} \& \mathrm{E}$ for a blood test and contact your GP.

We would like to know why this has happened and why dental staff are no longer covered. Isn't this what Occupational Health is for? Or are dental staff less important than hospital staff?

Everyone knows how busy A\&E can be (if your head is still on your neck you are okay). Is $A \& E$ prepared for this and can they deal with it if someone has a sharps injury from a patient who has Hepatitis or HIV? Can you get the antibodies on time if necessary?

Why have we not been informed about these important changes when we get letters about smaller, less important things? Whose responsibility should this be?

We were totally shocked about the situation and hope we can get covered again by the Occupational Health Services.
Lynn Woods at the British Dental Association (BDA) responds:

Since the establishment of NHS England on 1 April 2013, a number of Area Teams (who replaced PCTs) have stopped NHS dental practices accessing local Occupational Health Services. The BDA and representatives of Local Dental Committees have challenged this disturbing change in policy. NHS England is now reviewing its position on providing access and has undertaken an audit to establish the scope and nature of occupational health services for all primary care professionals. The audit findings will be used to help NHS England formulate a national model for service delivery. Until this takes place, NHS dental practices should contact their local Area Teams to establish exactly who will provide advice and assistance if an inoculation injury occurs. Private practices should also make their own arrangements to ensure access to advice and assistance in dealing with inoculation injuries is in place.

\section{WE GET LITTLE OR NO THANKS}

We write in response to the letter on the autumn Vmail page of Vital, What are the benefits of registration? (page 5).

My dental nurse colleagues and I totally agree. We all work part time at a practice which has both NHS and private patients. We are all finding things extremely difficult. We pay all our own expenses: insurance, $\mathrm{CPD}$, registration, etc. No additional time off is given for CPD. We are all on 'no work no pay' contracts, paid a set amount a month (minimum wage). Our hours are worked as required (eg hours banked when not needed, etc).

We do not earn enough to pay tax, so have been told we are not entitled to any help - even though we pay all costs and launder our own uniforms. Several of us have applied for financial help (benefits, housing, tax credits, etc) to pay personal bills like rent etc as most of our wages go back into paying work costs. This is only to be told that there is very little help for us as none of our additional work expenses are taken into consideration. Even though without these we cannot work.

It is crazy to think we all studied hard to qualify as dental nurses, as well as working hard trying to do the job to the best of our ability. We get very little to no thanks, support or respect. Most of the job satisfaction seems to have vanished. It is as if the powers that be want us to quit our jobs as dental nurses.

We still come across patients who think our jobs are easy; 'cleaners with glorified titles' was one of many comments. We may be registered, but we feel that there is very little public knowledge of what we really do; what we need to learn to qualify; and the fact that we have so much commitment - physically, mentally and financially.

It's very rare nowadays that a patient will say thank you to us nurses, but it is nice when they do.

We thought it was about that that we had our say; sorry to those who don't agree. These are just our views. We wonder how many other dental nurses are in the same position.

Thank you for taking the time to read this.

\section{Jay and team}

